\title{
Consortium Capabilities for Enterprise Blockchain Success
}

\author{
Matt Kaufman, Stanton Heister, Kristi Yuthas
}

Portland State University, USA

Correspondence: matthew.kaufman@pdx.edu

Received: 14 May 2021 Accepted: 1 August 2021 Published: 24 August 2021

\begin{abstract}
Enterprise blockchain projects have great promise. They can cut costs and promote efficiency through disintermediation, increase transparency for tracking intercompany transactions, expand knowledge through consortia databases, and improve workflows through shared business processes. Despite its potential, blockchain technology has failed to produce promised benefits for enterprise networks. While the underlying technology has advanced rapidly, managerial capabilities needed to form and manage blockchain consortia have lagged, and as a result, few consortia have succeeded. This chapter reviews the extant literature on blockchain consortia and provides a framework that identifies (1) foundational conditions that precede effective consortium formation, (2) capabilities required for effective consortium functioning and evolution, and (3) partner and ecosystem-level outcomes associated with successful blockchain projects.
\end{abstract}

Keywords: enterprise blockechain, blockechain consortium, blockchain consortia, strategic capabilities, success factors

JEL Classifications: M15 IT Management

\section{Introduction}

Blockchain technology has the potential to fundamentally change the way businesses collaborate and to solve business problems in ways not previously possible [1, 2, 3]. Promised benefits include streamlined processes, cost savings, risk reduction, and improved stakeholder relationships [4]. Despite its potential, the technology has not been widely adopted and early adopters have encountered problems and challenges [5]. While the underlying information technology continues to advance rapidly, the development of business capabilities necessary for creating and capturing value continue to lag [6]. This is particularly true for consortium blockchain solutions, which require the formation and governance of cooperative networks [7].

Consortium blockchains are interorganisational systems that enable organisations to integrate their business operations and data [8]. For such systems, the organisational component is critical because people, their ideas, and decision-making processes are all affected [9]. Networks of organisations and associated business workflows span supply chains or industries, and in some cases, external stakeholders [10]. Participants may include trading partners along supply chains that serve a shared base of end customers; they may be made up of competitors operating in the same industry sector; they may include a mix of public and private firms. Although participating organisations vary, the hallmark of consortia is that the partners collaborate to solve shared problems [11].

Blockchain projects require a broader range of business capabilities than do typical enterprise alliances [6]. Blockchain consortia are complex organisational arrangements where partners must collaborate on the purpose, operations, and desired outcomes of the project, which represent a new way of organising interfirm collaboration [1]. Member firms, and the consortium as a whole, must possess a variety of skills and attitudes. Because blockchain is typically treated as a technology problem, the business capabilities required for successful consortia are not widely recognised or discussed. While scholarly literature is beginning to emerge, it focuses primarily on technological issues and ignores or minimises organisational complexities $[5,12,13]$.

In the remainder of this chapter, we review the extant literature on blockchain consortia and examine the capabilities needed for the successful formation and management of these solutions. Although several studies touch on consortium governance, we note a significant gap in research addressing criteria associated with consortium effectiveness. We build upon academic research and trade literature to propose a framework that identifies (1) foundational conditions that precede effective consortium formation, (2) capabilities required for effective consortium functioning and evolution, and (3) partner and ecosystem-level outcomes associated with successful blockchain projects. We believe that the ability to effectively form and manage blockchain consortia plays an important role in promoting value co-creation and capture and in supporting innovation. By presenting a framework based on systematic research, our aim is to contribute to these objectives.

\section{Literature Review}

To summarise current studies focused on blockchain consortia, we conducted a systematic literature review using 
the Web of Science academic database in June 2021. To ensure the broadest possible coverage, our search includes results for: enterprise blockchain or blockchain consortia or blockchain consortium. No date restrictions were used to ensure comprehensive results. Two important trends emerge from the 425 papers returned.

First, enterprise blockchain and blockchain consortia are a relatively new and quickly growing area of study. Results span an approximately four-year period, with the earliest published in July 2017 and the latest scheduled for publication in August 2021. Seven papers included in the results were published in 2017, while 135 (32\% of the total) were published or available for early access during the first half of 2021.

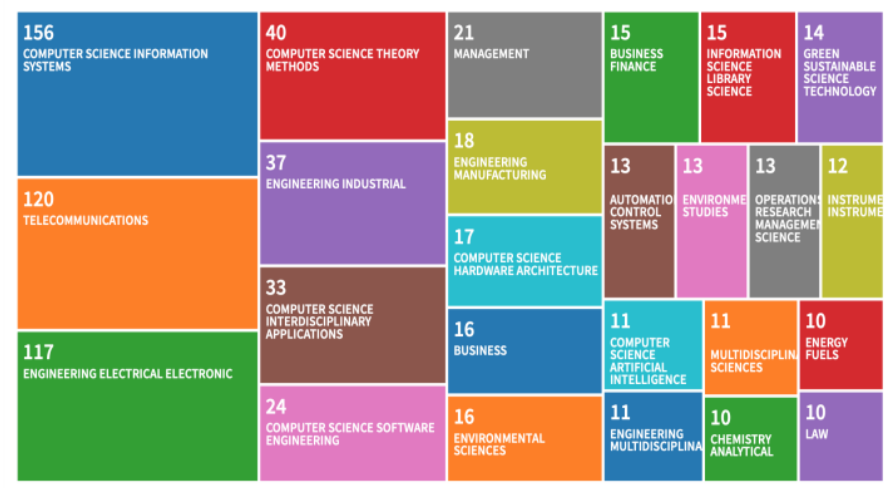

Figure 1: Web of Science Search Results by Discipline.

Second, enterprise blockchain and blockchain consortia are of interest to a diverse set of academic disciplines. Figure 1 aggregates search results into a visualisation comparing the number of results returned by discipline. The chart highlights the extent to which enterprise blockchain concepts are largely studied within disciplines that solve technical challenges preventing adoption and widespread use. A review of the results for various subdisciplines associated with computer science, telecommunications, engineering, and other hard science disciplines show rapid progress on technical challenges preventing adoption. While interesting and important, these findings are not the focus of this chapter.

Instead, we focus on the social and governance challenges that must be overcome to establish enterprise blockchains as a tool for strategic value creation. As such, we highlight the 71 results returned for various socialscience subdisciplines associated with business, management, finance, information science, operations, and law for additional analysis. ${ }^{1}$ Each of these articles was reviewed and categorised according to the paper's motivation and contribution. In all, we identified seven article categories.

\footnotetext{
${ }^{1}$ The three articles excluded from further analysis include an introduction to a special issue, in one, and two other articles in which the study of blockchain technology was not a primary focus.
}

Table 1: Analysis of Literature Results by Category

\begin{tabular}{|l|c|c|}
\hline Topic of Article & Count & Percent (\%) \\
\hline Applications & 39 & 55 \\
\hline Technical overview/proof of concept & 9 & 13 \\
\hline $\begin{array}{l}\text { Adoption challenges/ } \\
\text { determinants/consequences }\end{array}$ & 7 & 10 \\
\hline Privacy/security/regulation & 6 & 8 \\
\hline Cryptocurrency & 3 & 4 \\
\hline Literature review & 3 & 4 \\
\hline $\begin{array}{l}\text { Consortium formation and } \\
\text { governance }\end{array}$ & 4 & 6 \\
\hline Total & 71 & 100 \\
\hline
\end{tabular}

Web of Science Subdisciplines Included: Business, Finance, Information Science, Law, Management, and Operations.

Table 1 presents our categorisation of the motivation and contribution of papers selected for further analysis. The most common type of paper included within the subset is the application of blockchain technology to a specific task or market. Such articles make up 55\% of the total. Each of these papers discusses how the application of blockchain technology could reduce cost or improve performance within a specific setting. Highly cited examples include the description of benefits to blockchain adoption in supply chain/manufacturing $[14,15,16,17]$, accounting/auditing [15, 18], financial services [19, 20], healthcare [21, 22, 23, 24], and utility markets [25]. While these papers make significant contributions to the general understanding and proliferation of blockchain technology, they do not focus on the unique challenges involved in consortium formation and governance.

The second most common type of paper included within the subset is a technical overview or proof of concept for a specific improvement to the blockchain ecosystem. Such articles make up $22 \%$ of those selected for additional analysis. Examples include summaries of technical developments in certain areas or within the blockchain ecosystem as a whole [26, 27], security/privacy [28, 29, 30], latency [31], error management [32], and consensus mechanisms [33, 34]. Technological issues have long concerned companies exploring blockchain adoption. Firms need to know that the solutions they invest in will continue to meet their needs over time. Such contributions help to overcome technical challenges within the blockchain ecosystem but do not focus on challenges related to consortium formation and governance.

Other categories within the identified subset include analyses of challenges, determinants, or consequences of blockchain adoption $(10 \%)$ [35, 36, 37]; discussion of privacy, security, or regulatory challenges $(8 \%)[38,39,40,41]$; a focus on cryptocurrency (4\%) [42, 43]; or literature reviews (4\%) [44, 45]. A final category includes papers that explicitly deal with the primary focus of this chapter: challenges related to consortium formation and governance $(6 \%)$. As this category contains studies related to the primary concerns of this chapter, we will briefly summarise relevant examples. 
Lacity [46] uses a series of cases to propose a set of questions organisations should consider when considering enterprise blockchain applications. The author provides an overview of circumstances where blockchain is preferable to other database solutions, and notes a variety of resources that could be used to develop viable solutions. Resources discussed include relevant standards, regulatory considerations, and shared governance models.

Zavolokina et al. [47] highlight trust, collaboration, and regulatory compliance as key inputs for blockchain consortium success. Their case analysis suggests a set of strategies that include initial membership of non-competing organisations, segregated platform/private and infrastructure/public benefits, and separate short- and long-term priorities.

Nathan and Jacobs [48] provide a brief overview of consortium strategy considerations alongside a discussion of blockchain applications in financial services. They emphasize the need for an overarching vision or strategy to guide consortium formation, membership criteria, technology supported, governance process, data management, and regulatory concerns. While discussion of each topic within the paper is of limited depth, each of the topics raised is important topics for future research and development.

Finally, Schwabe [49] examines the unique role public agencies can play within blockchain consortia. While the paper does not explicitly focus on consortium formation and governance, it does emphasise the need for data access, user trust, and data quality. Mechanisms for achieving those goals beyond public agency participation are not discussed.

\section{Consortium Capabilities Framework}

While technology continues to advance, the organisational factors that drive enterprise blockchain success need additional attention. Blockchains span technical, functional, social, and legal boundaries within business [50]. Consortia must harmonise diverse stakeholder views within companies and across the broader network in order to be successful [51]. As a result, blockchain solutions require consortium partners to share information and coordinate in new ways.

Process coordination and data sharing across organisations is an entirely new way of doing business for some participants [52, 53, 54]. Hurder [55] describes blockchain platforms as economic systems: "Blockchain-based consortia allow enterprises to share, buy, and sell valuable data and use that pooled data to create new goods and services which can then be monetized." The paper notes network effects that result from the number of partners in an ecosystem, driving growth in value as more members are added to the consortium network and as costs can be spread among them [55]. Despite the potential for such benefits, forming and operating consortia may require members to accept agreements that challenge long-held belief systems or underlying business models [56]. Such collaboration may require changes to workflows, business models, and corporate strategy at the highest level [46]. It demands strategic, organisational, and market coordination that is able to address all stakeholder interests [57].

The success of an enterprise blockchain project relies on the effective creation and management of consortia. This requires certain enabling conditions to be present prior to consortium formation and for the consortium to possess a number of core capabilities that enable it to effectively organise and govern activity [47]. Business leaders understand the potential benefits to blockchain consortia but remain concerned with issues around "co-opetition," or partnering with competitors or pseudo-competitors, even though such collaboration is critical [1, 50]. When collaboratively developed and managed, a consortium is positioned to benefit individual partners and the broader ecosystem [47]. When they are not, the blockchain project will likely fail to deliver anticipated benefits. Despite the importance of coordination and planning, Naqvi and Hussain [58] find that many projects fail to use high-quality evidence and critical appraisal to evaluate projects before they are implemented or after they are in operation.

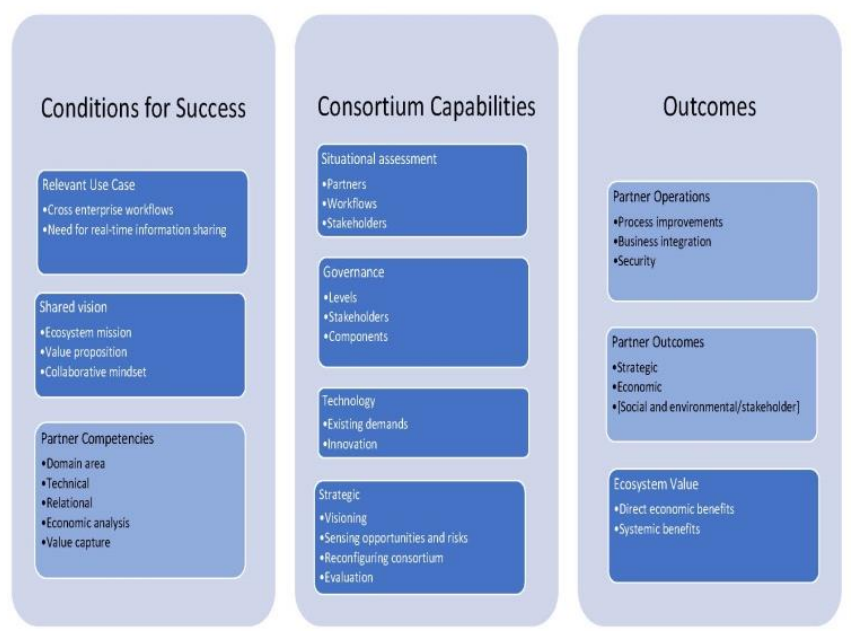

Figure 2: Consortium Capabilities Framework.

Figure 2 depicts a blockchain consortium capabilities framework that describes inputs, processes, and outputs associated with successful consortia. Partner-level factors are lightly shaded. Consortium-level factors are darkly shaded. Conditions for success are inputs and necessary antecedents to effective blockchain consortia. These conditions primarily refer to the blockchain's promise for addressing problems shared by the consortia, or factors driving member buy-in and fitness for participation. Consortium capabilities are processes or capabilities possessed by the consortium as a whole. Collectively, consortium participants must have the capacity to assess current functions and resources, govern the consortium effectively, maintain technological strengths, and act strategically to ensure the long-term effectiveness of the consortium. Outputs include intermediate and long-term performance improvements and value creation for both individual participants and the consortium as a whole. 


\subsection{Conditions for Success}

The first section of the framework outlines the initial conditions necessary to form successful consortia. These conditions should be present or be developed before the consortium partnership is formalised. They include both consortium-level and individual-partner-level capabilities. A proposed use case should be one where a traditional system is not well-suited, blockchain offers superior performance, and initial participants share a vision for what the consortium can accomplish. Individual partners joining the consortium should possess or build the technical and administrative capabilities that will be needed to participate in and benefit from the network.

\subsubsection{Relevant Use Case}

The success of a blockchain solution rests on the development of an appropriate use case. There are many decision models for determining whether a particular use case can be best solved using blockchain. Wust and Gervais [59] suggest that a private permissioned blockchain is appropriate when the state of assets or agreements must be recorded by multiple, known parties and for which a trusted-third-party solution is unavailable or is more costly than a blockchain solution. PwC [60] adds the condition that transactions created by different participants are time-sensitive interactions, such that the ability to rapidly share information has business benefits. Naqvi and Hussein [58] through The Centre for Evidence Based Blockchain provide a more expansive analysis. They provide a comprehensive framework that can be used by organizations and consortia to anticipate and evaluate the probable outcomes of various blockchain use cases.

The existence of cross-enterprise workflows and multi-party transactions helps to develop a clear and relevant use case to drive successful adoption [61]. For example, supply chain consortia may include partners engaged in coordinated planning for material movement and handoffs or for shared regulatory compliance; finance industry consortia may share costs associated with customer verification and anti-money laundering requirements; cross-industry consortia may share scarce resources such as docking locations in a port or space inside a grain silo. The ability to share information in a validated, secure, and up-to-date format, or to automate actions through smart contracts, can create benefits for all parties [61].

The need for real-time information sharing presents a clear advantage for blockchain solutions. Traditional enterprise resource planning (ERP) and other enterprise systems do not share information easily, and in some sectors, rely on outdated electronic data interchange (EDI) systems or even on emailed spreadsheets [62]. This can result in delayed access to information, wasted time, and reconciliation difficulties due to error or fraud [63]. Blockchain systems allow partners to record, share, and aggregate data in real time. The result is greater visibility of activities and more immediate decisions.

\subsubsection{Shared Vision}

Prospective partners must have a shared vision for a blockchain project's purpose and benefits to attract the investment and commitment necessary for project success. Each individual participant may benefit differently, but the consortium must agree upon collective benefits from collaboration and share an understanding of how they will be realised through the blockchain network.

Participants need a shared ecosystem mission. This mission shapes the current and future contours and benefits for the jointly developed distributed system. Problems arise when a blockchain addresses important issues for its founding organisations but fails to provide the same level of benefit for future participants. This was a problem for the IBM Maersk Trade Lens blockchain as it sought to expand. German company Hapag-Lloyd would not join a consortium controlled by competitors Maersk and IBM until the platform made governance changes that benefitted the industry more broadly [64]. Ideally, consortia will be formed and they grow with a high-level ecosystem mission associated with transparency, security, provenance, and equality. While participants will have their own reasons for joining, the ecosystem as a whole should have a mission that supersedes the interests of a few powerful partners.

A positive value proposition for every blockchain participant is essential. Blockchain participation and its associated process and technological changes make the technology costly and risky. These investments must be outweighed by the value created and captured by every current and future blockchain participant. While each initial participant in a consortium must weigh its own costs and benefits, many fail to anticipate the return on investment for future members. In many cases, network effects are realised when the value of the network for an individual participant increases as the network grows [65], so it is important to anticipate the likely business case for those who might join in the future.

Blockchain requires a collaborative mindset in which value is generated through cooperation. Strategic positioning and strategic advantage are based on the philosophy that companies achieve long-term success when they consistently outperform competitors, but such thinking can be counterproductive for blockchain consortia. Many large companies participate in strategic alliances that are built on cooperation, or often more aptly "co-opetition," but these are often short-term collaborations among a small group of partners. Blockchain consortia typically have no predetermined endpoint and include tens, hundreds, or thousands of participants. Participants must collaborate to securely share processes, information, or other resources. Partners must govern the network in a manner agreeable to current and future participants. The World Economic Forum [66] states "it is critical to reach agreement on not just the initial value levers to be pursued by the ecosystem but also the longer-term vision to be pursued.' 


\subsubsection{Partner Competencies}

Partners in a blockchain collaboration can benefit from a number of competencies required to develop and manage a consortium that generates value. Individual competencies will strongly influence whether the partner will achieve a return from blockchain investment. Further, individual partner success is instrumental in the success of the consortium.

Blockchain participants benefit from prior domain area knowledge and expertise related to the blockchain solution in development. Companies typically collaborate in areas where they are already subject matter experts, such as financial services for R3 or track and trace for FoodTrust. In some cases, however, companies explore blockchain solutions that extend beyond current expertise. TaxChain, for example, enables importers to validate trade certificates and the Plastic Bank provides a way for companies to provide evidence that they are achieving claimed sustainability goals. Although some of the partners in these blockchains have domain area expertise, others need to develop expertise in order to maximise potential value from the blockchain project.

Distributed technologies are new and require significant technical knowledge and development expertise in participating organisations. While many blockchain projects are guided by SaaS providers such as IBM and Accenture [67], participants typically need a level of blockchain competence in their IT functions. Information stored on the blockchain will flow to, or be compared with, information in the company's ERP and other systems. IT staff will need to integrate these systems appropriately. Control and permissioning of blockchain access must also be managed, and technologists will need processes for key assignment and management. Many firms will need blockchain-specific skills, such as the ability to manage a validator node and maintain consensus with other partners.

Technology staff may also need the ability to understand, test, modify, and create smart contracts or to oversee those functions. Pre-audited contract templates are increasingly available, and contract developers and auditors can be engaged for idiosyncratic contracts. High-level applications facilitate the creation and testing of smart contracts and the use of predeveloped code libraries or domain-specific apps. IT staff may be tasked with using these solutions.

Relational capabilities allow firms to establish and maintain beneficial relationships with partner organisations. Relationships enable a firm to access information and resources necessary for project success that would otherwise be unavailable. Blockchain consortia may include companies that have no prior relationships, or have a past history of ineffective partnership. Individual blockchain participants need to form relationships with transacting partners that enable collaboration in transaction processing and governance decisions. For partners with whom they will transact directly, firms also need the ability to collaborate on restructured business processes to accommodate effective blockchain innovation and use.
Blockchain projects have been described as mini-economies [11], which suggest a need for platform-level economic analysis. Participants in these projects contribute numerous resources to system development and maintenance. Firms need the ability to evaluate the economic benefits associated with these investments. These systems are often designed to reduce inefficiencies and smooth frictions in marketplace interactions [68]. Their economic benefits may flow from coordination, the ability to immediately and economically share information, the ability to ensure execution and manage risk through smart contracts and control, and the ability to maintain data and regulate permissions.

Blockchain solutions provide numerous opportunities for value creation and value capture by consortia members [6]. Operational benefits from enterprise blockchains include reduced costs through disintermediation or enhanced reconciliation, improved processes through enhanced coordination and information sharing, and reduced counterparty risks. These solutions create opportunities for new sources of competitive advantage through the development of new products, processes, or business models. Companies with the capacity to sense and seize these opportunities will need to reconfigure their organisations in order to capitalise on them. Successful firms will be poised to extract value from their participation in enterprise blockchain consortia. Participants will also gain competencies that enable them to capitalise upon future blockchain projects should the opportunity arise.

\subsection{Consortium Capabilities}

Consortium capabilities are necessary competences for a consortium to survive, evolve, and continue to produce value for its members. These competencies exist at the consortium level rather than at the individual participant level. Some consortia are structured as stand-alone entities while others take the form of alliances between independent partners. No matter the structure, the consortium will need capabilities that differ from those of the individual partners. Participants possess diverse capabilities and differentially contribute to consortium success. Each organisation will have its own strategic expertise but will also benefit from consortium capabilities distributed across the network.

\subsubsection{Situational Assessment}

Situational assessment is an ability to monitor and assess the resources, assets, and other benefits possessed by or available to consortium participants. Because the framework addresses the consortium's strategic, technical, and governance capabilities separately, the focus here is on consortium operations. A consortium needs to regularly assess its resources and whether they are consistent with day-to-day needs. Resources include financial contributions by partners or generated by the consortium, the technology currently possessed, data owned and controlled, human resources dedicated to consortium operations, brand or reputation, relationships between the 
consortium and outsiders such as regulators or potential technology providers, and other tangible and intangible assets that could be used to create value.

Assessments will also examine current partners and their level of commitment to the consortium - including their ongoing commitment and support for the consortium's current and strategic goals. A consortium should monitor its ability to cultivate potential partners, attract new partners, and retain existing partners. As appropriate, the consortium might also assess the degree to which it is successful in attracting highprofile partners and partners that possess specific desired capabilities or resources.

Regular documentation and assessment of workflows is another opportunity to provide value. As partners move into and out of roles and committees, they will need to understand how the day-to-day work of the consortium is accomplished. Workflows associated with partner relationships should be documented and shared at the consortium level, as shared IoT and communications standards and workflows increase the consortium's value to partners [61]. A full shared knowledge base of past, present, and planned workflows can also be valuable.

Regular assessment of external actors' needs and expectations from a consortium is also important. All actors that affect or are affected by the consortium's operations should be identified, with inputs and impacts regularly evaluated. Examples include governing bodies, standards organisations, tax and customs authorities, financing organisations, nonpartner suppliers and customers of the consortium, and media. Regular and thorough situational assessment and communication of this information among consortium partners lays the groundwork for ongoing work around strategy and governance.

\subsubsection{Governance}

Effective governance is perhaps the most foundational element in blockchain success. Managing governance among a group of partners can prove challenging as enterprises will differ in their priorities, profit and loss models, and business processes [69]. Aligning standards, designing consistent codes of conduct across industries, and ensuring stakeholders of all sizes have input [70]. Successful governance should encourage the continued development of industry standards, formal business processes, and other best practices.

However, governance is an expansive topic and there continue to be misconceptions about the core concept. Allen and Berg [71] argue that "blockchain governance relates to the way decisions are made, not the decisions themselves - who chooses and how choices are made, rather than what is chosen." Successful consortia require endogenous and exogenous governance mechanisms [71]. Endogenous governance refers to consensus mechanisms and other control procedures built into blockchain platforms. Exogenous governance refers to formal and informal agreements about the network itself, such as processes for admitting new participants or voting on platform changes. Tasca and Tessone [72] also recognise external factors affecting governance, including regulatory frameworks and industry policies. Van Pelt et al. [73] describe three layers of governance: on-chain protocol, which refers to rules encoded in the platform; offchain development, which refers to the real-world processes related to governance of the protocol; and off-chain community, which refers to how the broader community defines and is tied to the blockchain.

Blockchain networks have many stakeholders, who pursue unique outcomes through participation in blockchain consortia. Governance helps coordinate the rights, responsibilities, actions, and incentives of diverse stakeholders with the overarching goal of network survival and growth. Blockchain governance agreements have the potential to support or even replace traditional forms of corporate governance such as legal contracts or behavioural norms [1]. Blockchain governance agreements therefore may be of interest to C-level executives and boards. Van Pelt et al. [73] provide a framework for blockchain governance based on extensive research and validation. The framework has six major components: formation and context reflecting the blockchain purpose and ideology, roles that determine responsibilities and accountability, incentives that motivate community members, membership processes for blockchain participation, communication relating to coordination and performance, and decision-making processes such as consensus and conflict resolution. Successful blockchain consortia must possess the capability to effectively enact and manage each of these six components, which will begin prior to the formation of the consortium and continue as it evolves.

\subsubsection{Technology}

Whether the consortium builds its own platform or relies on a software-as-a-service provider, technical expertise will be required to support normal platform activities and innovations to improve the functioning of the blockchain network. The consortium must possess the skills necessary to support the existing demands on a blockchain system, both at its inception and as the network grows, when partners join and leave, and platform functionality evolves.

The technological skills necessary to incorporate innovation through fundamental changes to the blockchain architecture is also a necessary consortium-level capability. Blockchain evolves rapidly. Improvements to core mechanisms of the underlying blockchain technology continue at a rapid pace. Examples include improvements to consensus mechanisms, data storage solutions, and protocols for interoperability that enable the sharing of assets and processes across networks. Technologists need the ability to stay abreast of these developments and to determine their appropriateness and compatibility with existing consortia structures and goals. When these innovations can provide significant benefits, technologists will need to plan and oversee system changes. Blockchain technology is still new, and innovations in the capacity and uses of these systems are 
continually introduced. A consortium needs the ability to understand how such innovation might enable or constrain the achievement of its strategic vision and develop plans to respond and adapt accordingly.

\subsubsection{Strategic}

Effective consortia need a shared strategic vision and mission to ensure success. Ongoing effectiveness requires the ability to manage and redesign the ecosystem's mission, respond to ecosystem learning, and adapt to environmental changes. Successful deployment of blockchain solutions "requires a shift to thinking in terms of the ecosystem" and a mindset that "allows organisations to move beyond what's traditionally possible for them within the confines of their own vertically integrated operations" [66]. A consortium must possess strategic capabilities to manage performance at the ecosystem level.

Strategic factors that influence the success of a blockchain consortium are many and varied. The consortium needs the capacity to sense opportunities and risks, which may include the introduction of competing consortia, partners joining and leaving the network, evolution of trade or industry standards, or new regulations. Consortia without the ability to respond to these risks will struggle to succeed within a rapidly changing marketplace. Working with IT, strategists can benefit from regularly scanning the environment for technological developments in blockchain and related technologies. The integration of IoT and artificial intelligence for writing and analysing records may promote the goals of the consortium and its stakeholders. Strategists should also foresee potential benefits that arise as the network scales and plan to translate into financial returns. Revenue-generating opportunities and new ways to monetise data should be anticipated and explored. Lessons can be learned from new use cases in related, or unrelated, contexts that have parallel sets of goals and constraints.

Successful consortia not only need to manage risk and seek out new opportunities; they need to be able to reconfigure the consortium accordingly. Effective digital transformation and dynamic learning capabilities enable blockchain participants to effectively form and execute strategies to capitalise on emerging risks and opportunities. Effective change management will require collaboration and coordination with consortium stakeholders about shifts in situational assessment, governance, and technology. Communication with consortium stakeholders will be crucial as changes are proposed with shifts in responsibilities and impact [74].

The success of a consortium hinges on its ability to create value for its participants, the broader ecosystem, and its partners. A consortium's ability to evaluate both network and individual member outcomes is of crucial importance. While the value proposition is addressed before a company decides to participate, evaluation mechanisms must be in place to determine whether the project lives up to expectations for costs and value creation. These evaluations inform the need for changes in governance and direct collaboration with other partners. Naqvi and Hussain [58] outline a process for blockchain evaluation based on widely accepted, evidencebased research and evaluation processes. They suggest effective evaluation comes from a clear definition of the problems to be addressed and a critical evaluation of both existing solutions and the new system at the initiation of the blockchain project [58]. Ongoing analysis of project performance provides evidence that can be assessed by current stakeholders as well as by independent evaluators.

\subsection{Outcomes}

Participation in blockchain consortia provides a broad range of outcomes for both individual participants and the broader ecosystem. We separate these outcomes into three categories. The first is partner operations, which refers to direct effects of the blockchain on day-to-day activities. The second is partner impacts, which are the longer-term financial and other impacts enabled by participation in the consortium. Third is ecosystem value. The ecosystem itself, with its growing database of blockchain transactions and network participation, generates value in a number of ways.

\subsubsection{Partner Operations}

Exploring the whole range of direct and indirect benefits and costs is essential for understanding the potential or realised value of an enterprise blockchain for its participants. Commonly discussed benefits include increased efficiency, reduced costs and risks, and enhanced customer experience [74].

Process improvements are often the driver for blockchain implementation and participation. The ability to track each action in a workflow renders processes visible and creates opportunities for improvement. Evaluation of potential blockchain benefits often begins with the identification of pain points and frictions. The potential for an accurate, agreedupon transaction record to reduce paperwork-processing dispute resolution is a common source of improvement, as is the disintermediation resulting from reduced need for external verification. Similar to the implementation of ERP systems, participation in blockchain consortia encourages companies to reengineer their business processes for the blockchain environment [75].

A focus on business integration encourages participants in an enterprise blockchain to re-think and reengineer both external and internal company processes [56]. In some cases, consortium participation enables processes to be shared or outsourced. For example, when one blockchain partner performs a "Know Your Customer" analysis to comply with anti-money laundering regulations, other partners can rely on that analysis and avoid incurring additional costs to trade with the customer. The adoption of industry best practices through process standardisation provides another opportunity for performance improvement [75]. 
Security enhancements available in blockchain environments further affect operations for many partners. Data, digital assets, and intellectual property can be secured and authenticated using cryptography, and consensus models reduce the potential for destruction or alteration of information [29, 30]. Decentralised identity functionality enables enhanced privacy for customers, employees, and transacting partners. It also enhances opportunities to minimise sensitive data collected and stored and reduces the need to secure such data. The level of cybersecurity maturity among participants increases through the validated provenance of all intercompany transactions recorded on the blockchain. In some cases, such agreements can be executed automatically [18].

\subsubsection{Partner Outcomes}

Blockchain use cases vary in their objectives and significance for blockchain partners. In some cases, blockchain solutions are integral to firm strategy. In other cases, they lead to economic outcomes, new or reformed relationships with consortium partners, and environmental and social impacts.

Strategic benefits can be gained in a number of ways. Adoption of blockchain technologies may contribute to reputational effects, as firms may be seen as forward-thinking or they may affect the firm's strategic goals directly. Yuthas et al. [6] provide examples of companies that have strengthened strategic capabilities in several ways. Some partners have built upon existing capabilities, for example, by using provenancebased systems to validate product claims. Others have built blockchain-specific capabilities such as developing expertise or consortium governance that can extend to future projects. Consortium platforms have also been used to share data and strategic resources, leading to the development of new projects and strengthened partner relationships.

Economic benefits arise through a variety of avenues. Operational improvement derives from reduced costs through the elimination of processes and intermediaries, or enhanced efficiency through process performance and reduced risk. Improvements in transparency and visibility improve planning and increase predictability in ways that enhance asset utilisation and delay the need for new capital investments [26, 44]. Improvements in service responsiveness and quality that result from redesigned processes can increase revenue by attracting new customers and reducing turnover. New products and business models can help partners to serve new markets or enhance services to existing markets. All of these changes allow firms to create and capture new sources of value.

Relational outcomes realised through ties between partners are established or strengthened through strategic collaborations [76]. Consortium participants may collaborate in a variety of ways. Smart contract-based business arrangements reduce the cost associated with establishing and maintaining trust with trade partners and improve relationships at the firm level [75]. The blockchain-driven redesign of business processes can also facilitate new relationships at the firm level. Participation in consortium-level initiatives can build relationships as members work together to resolve governance and technological issues. Strategic alliance experience suggests that relationships formed through one project can carry over to other collaborative efforts.

Environmental and social outcomes also result from blockchain efficiencies. Reduced use of paper resulting from increased digitalisation is a small but not trivial example of creating more sustainable business operations. Outcomes will vary by firm and industry, but can be significant. For example, the Digital Shipping Container Association (DCSA) is developing standards for a system that will help carriers move away from "hurry up and wait" itineraries towards reaching ports just in time to unload. This change has the potential to significantly reduce excessive use of fuel and, in turn, greenhouse gas emissions [77]. Digitalisation and blockchain-enabled connectivity in the maritime sector can be pivotal in reducing the industry's collective carbon footprint [78].

\subsubsection{Ecosystem Value}

Blockchain systems also create outcomes at the ecosystem level, providing potential benefits for all consortium members. Blockchain partnerships can take many forms, including relational agreements among participants and for-profit entities. Regardless of the specific form, a consortium will incur costs of operations and generate value at the ecosystem level, some of which can be distributed to partners.

Forrester's Total Economic Impact model identifies basic elements of direct economic benefits from blockchain systems in a study commissioned by IBM [79]. Costs of delivering a blockchain solution include costs of the pilot phase, costs of bringing the solution to commercial scale, and the ongoing costs of maintaining the system. Benefits to the blockchain provider or ecosystem include fees for joining the network, ongoing membership fees, and transaction and contract execution fees paid by partners for using the system.

Participation in blockchain consortia requires companies to shift focus away from capturing value through competition and towards the systemic benefits provided by collaboration. The collaboration supported by an enterprise blockchain can provide value to all partners by providing access to new, authenticated, and vetted trading partners on the network. Although these benefits are realised by individual companies, they are created by the consortium. Blockchain systems provide access to technological capabilities that may otherwise be unavailable to individual firms, particularly small producers that can pay membership and transaction fees but do not possess advanced skills or technology. Ecosystems enable sharing and reduction of regulatory, compliance, and lobbying costs as well as the costs of developing and implementing standards.

Improvements in performance for ecosystem partners provide additional benefits for partner stakeholders. Customers, for 
example, will ultimately benefit from increased efficiency and quality. Ecosystem success may likewise be associated with improved utilisation of assets and reduced waste across the network. This can provide both economic and environmental benefits as the footprint for the production and delivery of goods is decreased [80].

\section{Conclusion}

Companies are investing heavily in exploring blockchain technologies, and industry projections suggest a rapid growth of these technologies in numerous verticals. For this vision to be realised, business capabilities must catch up to technological capabilities. Business processes must be redesigned to take advantage of the many benefits the technology can provide. Organisations and their leaders must learn to effectively form and govern consortia and associated relationships.

The consortium capabilities framework presented in this chapter provides an overview of core business elements that can promote blockchain success. By developing and employing these capabilities at the firm and network levels, consortia can better realise the promise of this still-new technology. This framework fills a current void in the literature by providing a practical set of guidelines for companies and consortia to consider when building and maintaining their networks.

\section{Competing interests}

None declared.

\section{Ethical approval}

Not applicable.

\section{Author's contribution}

Kristi Yuthas, Matt Kaufman, and Stanton Heister are responsible for writing the manuscript, collecting data, proofreading, etc.

\section{Funding}

Not applicable.

\section{Acknowledgements}

Publication of this article in an open access journal was funded by the Portland State University Library's Open Access Fund.

\section{References}

[1] Fabrice Lumineau, Wenqian Wang, and Oliver Schilke, "Blockchain Governance-A new way of organizing collaborations?” Organization Science, 2020.

[2] S. Davidson, P. De Filippi, and J. Potts, "Blockchains and the economic institutions of capitalism," The Journal of Institutional Economics, vol. 14, (4), pp. 639-658, 2018.

[3] A. Dutra, A. Tumasjan, and I. M. Welpe, "Blockchain is changing how media and entertainment companies compete," MIT Sloan Management Review, vol. 60, (1), pp. 39-45, 2018.

[4] M. A. Engelhardt, "Hitching healthcare to the chain: An introduction to blockchain technology in the healthcare sector," Technology Innovation Management Review, 7, (10), 2017

[5] M. Janssen, V. Weerakkody, E. Ismagilova, U. Sivarajah, and Z. Irani, "A framework for analysing blockchain technology adoption: Integrating institutional, market and technical factors," International Journal of Information Management, vol. 50, pp. 302-309, 2020.

[6] Kristi Yuthas, Yolanda Sarason, and Asad Aziz, "Strategic value creation through enterprise blockchain," The Journal of The British Blockchain Association, 4, (1), pp. 3-10, 2021.

[7] K. W. Prewett, G. L. Prescott, and K. Phillips, "Blockchain adoption is inevitable-Barriers and risks remain," Journal of Corporate accounting \& finance, vol. 31, (2), pp. 21-28, 2020.

[8] F. Werner, M. Basalla, J. Schneider, D. Hays, and J. Vom Brocke, "Blockchain adoption from an interorganizational systems perspective-a mixed-methods approach," Information Systems Management, vol. 38, (2), pp. 135-150, 2021

[9] M. Ozturan, I. Atasu, and H. Soydan, "Assessment of blockchain technology readiness level of banking industry: Case of Turkey," International Journal of Business Marketing and Management (IJBMM), vol. 4, (12), pp. 0113, 2019.

[10] D. Ghode, V. Yadav, R. Jain, and G. Soni, "Adoption of blockchain in supply chain: An analysis of influencing factors," Journal of Enterprise Information Management, 2020.

[11] Elissar Toufaily, Tatiana Zalan, and Soumaya Ben Dhaou, "A framework of blockchain technology adoption: An investigation of challenges and expected value," Information \& Management, vol. 58, (3), pp. 103444 103461, 2021.

[12] Yogesh K. Dwivedi Hughes, Santosh K. Misra, Nripendra P. Rana, Vishnupriya Raghavan, and Viswanadh Akella, "Blockchain research, practice and policy: Applications, benefits, limitations, emerging research themes and research agenda," International Journal of Information Management, vol. 49, pp. 114-129, 2019.

[13] R. Ziolkowski, G. Miscione, and G. Schwabe, "Decision problems in blockchain governance: Old wine in new bottles or walking in someone else's shoes?," Journal of Management Information Systems, vol. 37, (2), pp. 316$348,2020$.

[14] H. M. Kim, and M. Laskowski, "Toward an ontologydriven blockchain design for supply-chain provenance," Intelligent Systems in Accounting, Finance and Management, vol. 25, (1), pp. 18-27, 2018.

[15] D. E. O'Leary, "Configuring blockchain architectures for transaction information in blockchain consortiums: The case of accounting and supply chain systems," Intelligent Systems in Accounting, Finance and Management, vol. 24, (4), pp. 138-147, 2017.

[16] A. Kumar, R. Liu, and Z. Shan, "Is blockchain a silver bullet for supply chain management? Technical challenges 
and research opportunities," Decision Sciences, vol. 51, (1), pp. 8-37, 2020.

[17] S. Rao, A. Gulley, M. Russell, and J. Patton, "On the quest for supply chain transparency through Blockchain: Lessons learned from two serialized data projects," Journal of Business Logistics, vol. 42, (1), pp. 88-100, 2021.

[18] J. Dai, and M. A. Vasarhelyi, "Toward blockchain-based accounting and assurance," Journal of Information Systems, vol. 31, (3), pp. 5-21, 2017.

[19] S. Yoo, "Blockchain based financial case analysis and its implications," Asia Pacific Journal of Innovation and Entrepreneurship, 2017.

[20] M. O’Dair, and R. Owen, "Financing new creative enterprise through blockchain technology: Opportunities and policy implications," Strategic Change, vol. 28, (1), pp. 9-17, 2019.

[21] T. Hardin, and D. Kotz, "Amanuensis: Information provenance for health-data systems," Information Processing \& Management, vol. 58, (2), p. 102460, 2021.

[22] J. Mattke, A. Hund, C. Maier, and T. Weitzel, "How an enterprise blockchain application in the US pharmaceuticals supply chain is saving lives," MIS Quarterly Executive, vol. 18, (4), 2019.

[23] S. Biswas, K. Sharif, F. Li, Z. Latif, S. S. Kanhere, and S. P. Mohanty, "Interoperability and synchronization management of blockchain-based decentralized e-health systems," IEEE Transactions on Engineering Management, vol. 67, (4), pp. 1363-1376, 2020.

[24] K. Miyachi, and T. K. Mackey, "hOCBS: A privacypreserving blockchain framework for healthcare data leveraging an on-chain and off-chain system design," Information Processing \& Management, vol. 58, (3), p. 102535, 2021.

[25] S. Höhne, and V. Tiberius, "Powered by blockchain: Forecasting blockchain use in the electricity market," International Journal of Energy Sector Management, 2020.

[26] L. D. Xu, E. L. Xu, and L. Li, "Industry 4.0: state of the art and future trends," International Journal of Production Research, vol. 56, (8), pp. 2941-2962, 2018.

[27] K. W. Prewett, G. L. Prescott, and K. Phillips, "Blockchain adoption is inevitable-Barriers and risks remain," Journal of Corporate accounting \& finance, vol. 31, (2), pp. 21-28, 2020.

[28] Y. Wang, and A. Kogan, "Designing confidentialitypreserving Blockchain-based transaction processing systems," International Journal of Accounting Information Systems, vol. 30, pp. 1-18, 2018.

[29] A. Vatankhah Barenji, Z. Li, W. M. Wang, G. Q. Huang, and D. A. Guerra-Zubiaga, "Blockchain-based ubiquitous manufacturing: a secure and reliable cyber-physical system," International Journal of Production Research, vol. 58, (7), pp. 2200-2221, 2020.

[30] M. Kuperberg, "Blockchain-based identity management: A survey from the enterprise and ecosystem perspective," IEEE Transactions on Engineering Management, vol. 67, (4), pp. 1008-1027, 2019.

[31] X. Xu, G. Sun, L. Luo, H. Cao, H. Yu, and A. V. Vasilakos, "Latency performance modeling and analysis for hyperledger fabric blockchain network," Information Processing \& Management, vol. 58, (1), p. 102436, 2021.

[32] A. Carvalho, J. W. Merhout, Y. Kadiyala, and J. Bentley II, "When good blocks go bad: Managing unwanted blockchain data," International Journal of Information Management, 57, p. 102263, 2021.

[33] H. Song, N. Zhu, R. Xue, J. He, K. Zhang, and J. Wang, "Proof-of-Contribution consensus mechanism for blockchain and its application in intellectual property protection," Information Processing \& Management, vol. 58, (3), p. 102507, 2021.

[34] Y. Zhang, L. Zhang, Y. Liu, and X. Luo, "Proof of service power: A blockchain consensus for cloud manufacturing," Journal of Manufacturing Systems, vol. 59, pp. 1-11, 2021.

[35] L. W. Wong, L. Y. Leong, J. J. Hew, G. W. H. Tan, and K. B. Ooi, "Time to seize the digital evolution: Adoption of blockchain in operations and supply chain management among Malaysian SMEs," International Journal of Information Management, vol. 52, p. 101997, 2020.

[36] X. Pan, X. Pan, M. Song, B. Ai, and Y. Ming, "Blockchain technology and enterprise operational capabilities: An empirical test," International Journal of Information Management, vol. 52, p. 101946, 2020.

[37] J. L. Hartley, and W. J. Sawaya, "Tortoise, not the hare: Digital transformation of supply chain business processes," Business Horizons, vol. 62, (6), pp. 707-715, 2019.

[38] K. Werbach, and N. Cornell, "Contracts ex machine,” Duke Law Journal, vol. 67, p. 313, 2017.

[39] L. Y. Yeh, P. J. Lu, S. H. Huang, and J. L. Huang, "SOChain: A privacy-preserving DDoS data exchange service over soc consortium blockchain," IEEE

Transactions on Engineering Management, vol. 67, (4), pp. 1487-1500, 2020.

[40] C. Reyes, C., "(Un) Corporate CryptoGovernance," Fordham Law Review, vol. 88, (5), p. 1875, 2020 .

[41] N. E. Vincent, and R. Barkhi, "Evaluating blockchain using COSO," Current Issues in Auditing, vol. 15, (1), pp. A57A71, 2021.

[42] P. Tasca, A. Hayes, and S. Liu, "The evolution of the bitcoin economy: Extracting and analyzing the network of payment relationships," The Journal of Risk Finance, 2018.

[43] R. Olsen, S. Battiston, G. Caldarelli, A. Golub, M. Nikulin, and S. Ivliev, "Case study of Lykke exchange: Architecture and outlook," The Journal of Risk Finance, 2018.

[44] T. Zheng, M. Ardolino, A. Bacchetti, and M. Perona, "The applications of Industry 4.0 technologies in manufacturing context: A systematic literature review," International 
Journal of Production Research, vol. 59, (6), pp. 1922 1954, 2021.

[45] S. Guerreiro, "Conceptualizing on dynamically stable business processes operation: A literature review on existing concepts," Business Process Management Journal, 2020 .

[46] M. C. Lacity, "Addressing key challenges to making enterprise blockchain applications a reality," MIS Quarterly Executive, vol. 17, (3), pp. 201-222, 2018.

[47] L. Zavolokina, R. Ziolkowski, I. Bauer, and G. Schwabe, "Management, governance and value creation in a blockchain consortium," MIS Quarterly Executive, Epubahead, 2020.

[48] J. Nathan, and B. Jacobs, "Blockchain consortium networks: Adding security and trust in financial services," Journal of Corporate Accounting \& Finance, vol. 31, (2), pp. 29-33, 2020.

[49] G. Schwabe, "The role of public agencies in blockchain consortia: Learning from the Cardossier," Information Polity, vol. 24, (4), pp. 437-451, 2019.

[50] A. Pólvora, S. Nascimento, J. S. Lourenço, and F. Scapolo, "Blockchain for industrial transformations: A forwardlooking approach with multi-stakeholder engagement for policy advice," Technological Forecasting and Social Change, vol. 157, p. 120091, 2020.

[51] Naseem Naqvi, "Editorial,” Journal of the British Blockchain Association, vol. 4, (1), p. 15, 2021.

[52] M. Swan, Blockchain: Blueprint for a new economy. O’Reilly Media, Sebastopol, CA, USA, 2015.

[53] A. Tapscott, Blockchain revolution: How the technology behind Bitcoin is changing money, business, and the world. Penguin, New York, NY, 2016.

[54] M. Iansiti, and K. R. Lakhani, "The truth about Blockchain," Harvard Business Review, vol. 95, (1), pp. 118-127, 2017.

[55] Staphanie Hurder, Why Enterprise Blockchains Fail: No Economic Incentives. 02 March 2020. Available: https://www.coindesk.com/why-enterprise-blockchainsfail-no-economic-incentives

[56] L. Pietrewicz, "Coordination in the age of industry 4.0," Economic and Social Development: Book of Proceedings, pp. 264-274, 2019.

[57] Dante Disparte, "Why enterprise blockchain projects fail," Forbes 20 May 2019. Available: https://www.forbes. $\mathrm{com} /$ sites/dantedisparte/2019/05/20/why-enterpriseblockchain-projects-fail/?sh $=2 \mathrm{~d} 271 \mathrm{c} 7 \mathrm{a} 4 \mathrm{~b} 96$.

[58] N. Naqvi, and M. Hussain, "Evidence-based blockchain: Findings from a global study of blockchain projects and start-up companies," Journal of the British Blockchain Association, vol. 3, (1), 2020.

[59] K. Wüst, and A. Gervais, "Do you need a blockchain?" 2018 Crypto Valley Conference on Blockchain Technology (CVCBT). Zug, pp. 45-54, 2018.
[60] PwC. Blockchain. 6 May 2015. Available: https://www.pwc.co.uk/blockchain.html

[61] N. Gaur, "Blockchain challenges in adoption," Managerial Finance, 2020.

[62] T. Jensen, J. Hedman, and S. Henningsson, "How TradeLens Delivers Business Value With Blockchain Technology," MIS Quarterly Executive, vol. 18, (4), 2019.

[63] L. Hsu, and M. Chen, "Impacts of ERP systems on the integrated-interaction performance of manufacturing and marketing," Industrial Management \& Data Systems, vol. 104, (1), pp. 42-55, 2004.

[64] O. Andersen, and L. Vogdrup-Schmidt, "Rivals reject blockchain solution from Maersk and IBM," 15 May 2018. Available: https://shippingwatch.com/carriers/Container/ article10602520.ece

[65] Amin Vafadarnikjoo, and Hadi Badri Ahmadi, and James J. H. Liou, Tiago Botelho, and Konstantinos Chalvatzis, "Analyzing blockchain adoption barriers in manufacturing supply chains by the neutrosophic analytic hierarchy process," Annals of Operations Research, 2021.

[66] World Economic Forum. Inclusive deployment of blockchain for supply chains: A framework for blockchain interoperability. Geneva: World Ecomomic Forum, 2020. Available: http://www3.weforum.org/docs/WEF_A_ Framework_for_Blockchain_Interoperability_2020.pdf

[67] IDC. A New IDC MarketScape Assesses Eleven Providers of Blockchain Services. 16 June 2020. Available: https:// www.idc.com/getdoc.jsp?containerId=prUS46572520

[68] C. Barrera, and S. Hurder, Cryptoeconomics: Designing effective incentives and governance models for blockchain networks using insights from economics. Toronto: Blockchain Research Institute, 2020.

[69] L. Laidin, K. Papadopoulou, and N. Dane, "Parameters for building sustainable blockchain application initiatives," The Journal of the British Blockchain Association, vol. 2, (1), 2019.

[70] Global Blockchain Business Council. Global Standard Mapping Initiative (GSMI) 2020. Geneva: Global Blockchain Business Council, 2020.

[71] Darcy W. E. Allen, and Chris Berg, "Blockchain governance: What we can learn from the economics of corporate governance," Journal of the British Blockchain Association, vol. 3, (1), 2020.

[72] Paolo Tasca, and Claudio J. Tessone, "Taxonomy of blockchain technologies: Principles of Identification and Classification," Ledger, vol. 4, 2019.

[73] Rowan van Pelt, Slinger Jansen, Djuri Baars, and Sietse Overbeek, "Defining blockchain governance: A framework for analysis and comparison," Information Systems Management, 2020.

[74] A. Banda, et al., IBM Blockchain: The founders handbook. Armonk: IBM, 2020.

[75] Shuchih Ernest Chang, Yi-Chian Chen, and Ming-Fang Lu. "Supply chain re-engineering using blockchain technology: A 
case of smart contract based tracking process," Technological Forecasting \& Social Change, vol. 144, pp. 1-11, 2019.

[76] R. Gulati, N. Nohira, and A. Zaheer, "Strategic networks," Strategic Management Journal, vol. 21, (3), pp. 203-215, March 2000, doi: 10.1002/(SICI)10970266(200003)21:3<203::AID-SMJ102>3.0.CO;2-K.

[77] DCSA. "Standards for a just-in-time port call." 2020.

[78] UNCTAD. Digitalizing the port call process. Geneva: United Nations, 2020.

[79] Forrester Consulting. Emerging Technology Projection: The Total Economic Impact ${ }^{\mathrm{TM}}$ Of IBM Blockchain. Cambridge: Forrester, 2018.

[80] Mahtab Kouhizadeh, and Joseph Sarkis. "Blockchain practices, potentials, and perspectives in greening supply chains," Sustainability, vol. 10, (10), p. 3652, 2018. 